\title{
Luminescence and excitation energy transfer in new fluoride crystals containing rare earth ions
}

\author{
W. Ryba-Romanowski*, P. Solarz, M. Gusowski, G. Dominiak-Dzik \\ Institute of Low Temperature and Structure Research Polish Academy of Sciences, ul. Okólna 2, PL-50422, Wroctaw, Poland
}

Received 19 December 2006; accepted 1 February 2007

\begin{abstract}
Spectroscopic characteristics of $\mathrm{Pr}^{3+}$ and $\mathrm{Eu}^{3+}$ in $\mathrm{K}_{2} \mathrm{Na}_{2} \mathrm{GdF}_{7}, \mathrm{~K}_{5} \mathrm{Li}_{2} \mathrm{GdF}_{10}$ and $\mathrm{K}_{3} \mathrm{GdF}_{6}$ fluoride matrices are considered. Crystal structures of these compounds have been ascertained based on X-ray measurement on single crystal samples. Energies of lattice vibrations have been derived from IR and Raman spectra. Spectroscopic features of crystals in the VUV region were studied using experimental facilities of the Superlumi station at HASYLAB in Hamburg. High-resolution spectra and decay curves of luminescence in the visible were used to determine the energy levels and excited state relaxation dynamics of luminescent ions. Relevance of energy transfer processes, which feed the ${ }^{5} \mathrm{D}_{J}$ levels of $\mathrm{Eu}^{3+}$ and the ${ }^{3} \mathrm{P}_{0}$ level of $\mathrm{Pr}^{3+}$, is discussed.
\end{abstract}

(C) 2007 Elsevier Ltd. All rights reserved.

Keywords: Fluoride crystals; Luminescence; Energy transfer; Vacuum ultraviolet

\section{Introduction}

Fluoride crystals are wide band-gap matrices that offer the opportunity to investigate the phenomena of excitation and relaxation of high energy levels within $4 \mathrm{f}^{n}$ configurations and lowest energy $5 \mathrm{~d}$ levels of rare earth ions. Knowledge on these phenomena was poor for long time because of experimental problems imposed by measurement in the VUV-UV spectral region combined with a lack of practical motivations. In early works, reported in the sixties and seventies of the last century, assignment of the VUV rare earth absorption bands in the wide band-gap matrices was proposed (Loh, 1966). A "catalogue" of VUV absorption spectra of rare earth ions in $\mathrm{CaF}_{2}$ was presented and interpreted in (Szczurek and Schlesinger, 1985). Recent increase in the interest in this field is stimulated by the search for new laser materials operating in the UV, scintillators and efficient phosphors that are able to convert the VUV emission of noble gases into the visible luminescence. An impressive number of the published works related to the optical

\footnotetext{
* Corresponding author. Tel.: +4871343 50 21; fax: +4871344 1029 .

E-mail address: W.Ryba-Romanowski@int.pan.wroc.pl

(W. Ryba-Romanowski).
}

spectra, excitation and relaxation processes and energy transfer involving transitions between high energy states within the 4f configuration and interconfigurational $4 \mathrm{f}-5 \mathrm{~d}$ transitions of rare earth ions has appeared during the last decade (Wegh and Meijerink, 1996; Krupa and Queffelec, 1997; Wegh et al., 1997; Wegh and Meijerink, 1999; Rodnyi et al., 2000; Makhov et al., 2000; Dorenbos, 2000; Karimov et al., 2001; Guyot et al., 2002; Wojtowicz et al., 2006). As a consequence, the phenomena mentioned above are rather well understood now.

\section{Concept of "photon-cutting"}

The photon-cutting (termed also "downconversion") is related to the ability of a luminescent material to emit more than one photon per one photon absorbed. This ability combined with the noble gas discharge may be useful in the design of mercury free luminescent light sources, provided that the photons are emitted in the visible region. The photon-cutting phenomenon involving transitions within the $4 \mathrm{f}^{2}$ configuration of $\operatorname{Pr}^{3+}$ was demonstrated in the past (Sommerdijk et al., 1974). It is depicted schematically in Fig. 1(a). Excitation of 5d levels by the VUV radiation is followed by nonradiative relaxation to the ${ }^{1} \mathrm{~S}_{0}$ level, which is located at about $50000 \mathrm{~cm}^{-1}$. From this 
a

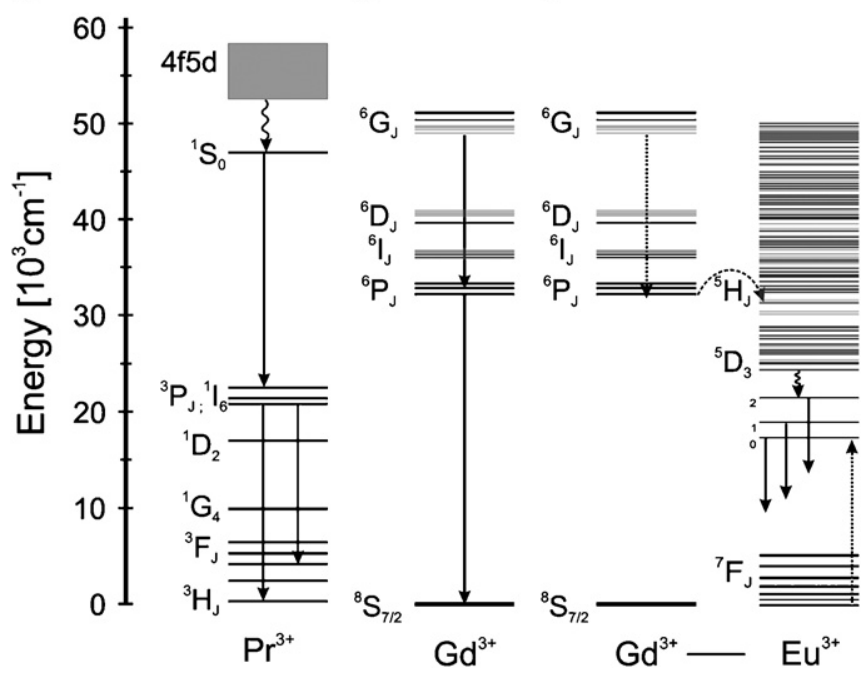

Fig. 1. Documented photon-cutting schemes in rare earth doped fluoride crystals. Dashed and solid arrows indicate nonradiative and radiative transitions, respectively.

level a two-step, cascade emission occurs. In the first step, the photons in the blue region are emitted at about $400 \mathrm{~nm}$. They are related to the ${ }^{1} \mathrm{~S}_{0}-{ }^{1} \mathrm{I}_{6}$ transition with the branching ratio approaching $60 \%$. In the second step, the visible emission associated with transitions originating in the ${ }^{3} \mathrm{P}_{0}$ level appears. This emission consists of several lines within the spectral region from about $460-750 \mathrm{~nm}$. The photon-cutting phenomenon is feasible when the ${ }^{1} \mathrm{~S}_{0}$ level is located beneath the lowest $5 \mathrm{~d}$ levels of $\mathrm{Pr}^{3+}$. Detailed study of this phenomenon in numerous praseodymium-doped fluoride matrices has been recently reported (Kück et al., 2005).

The photon-cutting involving transitions within the $4 \mathrm{f}^{7}$ configuration of $\mathrm{Gd}^{3+}$ was observed in 1996 (Wegh and Meijerink, 1996), for the first time. The corresponding energy level scheme and transitions are shown in Fig. 1(b). Excitation of the ${ }^{6} \mathrm{G}_{J}$ multiplets is followed by the radiative transitions from the ${ }^{6} \mathrm{G}_{7 / 2}$ multiplet to the ${ }^{6} \mathrm{P}_{J}$ multiplets, observed in the visible range. The second step of the process consists of the ${ }^{6} \mathrm{P}_{7 / 2}-{ }^{8} \mathrm{~S}_{7 / 2}$ transition at about $312 \mathrm{~nm}$. Shortcoming of these processes is related to the fact that the wavelengths of radiation emitted during the first step within $\operatorname{Pr}^{3+}$ ions and second step within $\mathrm{Gd}^{3+}$ ions are too short to be of practical importance. To account for this, the more complex system containing $\mathrm{Gd}^{3+}$ and $\mathrm{Eu}^{3+}$ ions was proposed and investigated (Wegh et al., 1997, 1999; Wegh and Meijerink, 1999). In the system depicted schematically in Fig. 1(c), nonradiative energy transfer from $\mathrm{Gd}^{3+}$ to $\mathrm{Eu}^{3+}$ follows the excitation of the ${ }^{6} \mathrm{G}_{J}$ multiplets of $\mathrm{Gd}^{3+}$, according to the relations:

$$
\begin{array}{ll}
{ }^{6} \mathrm{G}_{J}\left(\mathrm{Gd}^{3+}\right) \rightarrow{ }^{6} \mathrm{P}_{J}\left(\mathrm{Gd}^{3+}\right) ; & { }^{7} \mathrm{~F}_{1}\left(\mathrm{Eu}^{3+}\right) \rightarrow{ }^{5} \mathrm{D}_{0}\left(\mathrm{Eu}^{3+}\right), \\
{ }^{6} \mathrm{P}_{J}\left(\mathrm{Gd}^{3+}\right) \rightarrow{ }^{8} \mathrm{~S}_{7 / 2}\left(\mathrm{Gd}^{3+}\right) ; & { }^{7} \mathrm{~F}_{0}\left(\mathrm{Eu}^{3+}\right) \rightarrow{ }^{5} \mathrm{H}_{J}\left(\mathrm{Eu}^{3+}\right) .
\end{array}
$$

Next, the ${ }^{5} \mathrm{H}_{J}$ excitation is transferred to the emitting ${ }^{5} \mathrm{D}_{J}$ levels of $\mathrm{Eu}^{3+}$ by multiphonon relaxation. In this case all emitted photons are in the visible region. Efficiency of the

photon-cutting, expressed in terms of number of the emitted visible photons per number of photons absorbed at about $200 \mathrm{~nm}$, is close to $200 \%$. However, the overall conversion of the broadband emission of noble gas discharge to visible luminescence is far below $100 \%$ since the $\mathrm{Gd}^{3+}$ absorption lines are weak and narrow. In view of this shortcoming, an additional sensitisation with ions which show intense absorption in the 140-200 nm spectral region and are able to transfer the excitation to ions emitting in the visible would be very promising. In this context, a sensitisation by $\mathrm{Pb}^{2+}$ ions was considered recently (Babin et al., 2004). Energy transfer processes in such multiply doped systems depend strongly on the host. Therefore, the search for new wide band-gap matrices that are able to accommodate different luminescent ions seems to be justified.

\section{Experimental}

Nominally anhydrous fluorides $\mathrm{LiF}, \mathrm{NaF}, \mathrm{KF}, \mathrm{GdF}_{3}$ and $\mathrm{EuF}_{3}$ of $4 \mathrm{~N}$ purity were used as starting materials. All chemicals were dried under vacuum at about $200{ }^{\circ} \mathrm{C}$ to remove traces of water. Stoichiometric mixtures of fluorides corresponding to the desired compound composition were heated at high temperature in graphite crucibles to accomplish solid state reaction. Next, temperature was raised slightly above the melting point and then the furnace was cooled down slowly. All procedures of handling and heating were carried out in an atmosphere of dry argon. Single crystals were grown by the Bridgman technique.

High resolution luminescence spectra were excited in the visible using an Argon ion laser or an optical parametric oscillator (OPO) pumped by the third harmonic of a Nd:YAG laser and recorded with a fluorometer system. Luminescence decay curves were recorded using a Tektronix model TDS 3052 digital oscilloscope. Excitation and luminescence spectra excited in the VUV region were recorded using synchrotron radiation and the set-up of the Superlumi experimental station of the Synchrotronsstrahlungslabor HASYLAB at DESY in Hamburg.

\section{Results and discussion}

\subsection{Structural consideration}

Crystal structure of $\mathrm{K}_{5} \mathrm{Li}_{2} \mathrm{GdF}_{10}: \mathrm{Eu}$, was reported previously (Ryba-Romanowski et al., 2002). It is built from layers formed by $\mathrm{GdF}_{8}$ dodecahedra, $\mathrm{LiF}_{4}$ tetrahedra and $\mathrm{KF}_{6}$ octahedra. $\mathrm{Gd}^{3+}$ ions do not share ligands and the nearest $\mathrm{Gd}^{3+}$ ions are separated by more than $0.6 \mathrm{~nm}$. Owing to this features exchange interaction between rare earth ions are expected to be negligible and multipole interaction strongly reduced.

Crystal structure of $\mathrm{K}_{2} \mathrm{Na}_{2} \mathrm{NdF}_{7}$ has been determined quite recently (Solarz et al., 2004). Examination of the $\mathrm{K}_{2} \mathrm{Na}_{2} \mathrm{GdF}_{7}: \mathrm{Eu}^{3+}$ small single crystals revealed that substitution of $\mathrm{Nd}$ atoms by $\mathrm{Gd}$ atoms brings about smaller lattice constants but preserves the crystal structure. The $\mathrm{K}_{2} \mathrm{Na}_{2} \mathrm{NdF}_{7}$ host contains two kinds of nonequivalent distorted $\mathrm{NaF}_{6}$ octahedra. The $\mathrm{Gd}^{3+}$ ions occupy positions with the $C_{4 v}$ site symmetry in the centre of polyhedra with nine F ligands and form the 
Table 1

Structural characterisation of fluoride crystals

\begin{tabular}{|c|c|c|c|}
\hline & $\mathrm{K}_{5} \mathrm{Li}_{2} \mathrm{GdF}_{10}$ & $\mathrm{~K}_{2} \mathrm{Na}_{2} \mathrm{GdF}_{7}$ & $\mathrm{~K}_{3} \mathrm{GdF}_{6}$ \\
\hline Crystal system and space group & Orthorhombic Pnma & Cubic Im-3m & Monoclinic $\mathrm{P} 2{ }_{1} / n$ \\
\hline Symmetry of Gd site & $C_{\mathrm{s}}$ & $C_{4 v}$ & $C_{i}$ \\
\hline $\mathrm{Gd}^{3+}$ coordination number & 8 & 9 & 6 \\
\hline Minimal Gd-Gd distance (nm) & 0.681 & 0.363 & 0.644 \\
\hline Minimal Gd-F distance (nm) & 0.239 & 0.236 & 0.221 \\
\hline Density $\left(\mathrm{g} / \mathrm{dm}^{3}\right)$ & 3170 & 3788 & 3367 \\
\hline
\end{tabular}

Table 2

Spectroscopic features of $\mathrm{Eu}^{3+}$ doped crystals

\begin{tabular}{|c|c|c|c|}
\hline & $\mathrm{K}_{5} \mathrm{Li}_{2} \mathrm{GdF}_{10}: \mathrm{Eu}$ & $\mathrm{K}_{2} \mathrm{Na}_{2} \mathrm{GdF}_{7}: \mathrm{Eu}$ & $\mathrm{K}_{3} \mathrm{GdF}_{6}: \mathrm{Eu}$ \\
\hline \multicolumn{4}{|l|}{${ }^{2 \mathrm{~S}+1} \mathrm{~L}_{j}$ lifetime $(\mu \mathrm{s})$} \\
\hline${ }^{5} \mathrm{D}_{0}$ & 12500 & 6400 & 8400 \\
\hline${ }^{5} \mathrm{D}_{1}$ & 2845 & 1750 & 6000 \\
\hline${ }^{5} \mathrm{D}_{2}$ & 58 & 450 & 41 \\
\hline${ }^{5} \mathrm{D}_{3}$ & 240 & - & - \\
\hline \multicolumn{4}{|l|}{${ }^{2 \mathrm{~S}+1} \mathrm{~L}_{j}$ energy $\left(\mathrm{cm}^{-1}\right)$} \\
\hline${ }^{5} \mathrm{D}_{0}$ & 17279 & 17286 & 17273 \\
\hline${ }^{5} \mathrm{D}_{1}$ & $19025,19037,19059$ & 19034 & 19034 \\
\hline${ }^{7} \mathrm{~F}_{1}$ & $308,370,426$ & 263,294 & $290,373,437$ \\
\hline Cut-off phonon energy $\left(\mathrm{cm}^{-1}\right)$ & 680 & 425 & 465 \\
\hline
\end{tabular}

$\mathrm{Gd}_{2} \mathrm{~F}_{14}$ groups. Such pairs of $\mathrm{Gd}^{3+}$ ions are linked together by four common $\mathrm{F}^{-}$ions. The shortest distance of $0.36 \mathrm{~nm}$ between the neighbouring $\mathrm{Gd}^{3+}$ ions is relatively small.

Crystal structure of $\mathrm{K}_{3} \mathrm{GdF}_{6}$, determined at $300 \mathrm{~K}$, is composed of the distorted $\mathrm{GdF}_{6}$ and $\mathrm{K}(1) \mathrm{F}_{6}$ octahedra and $\mathrm{K}(2) \mathrm{F}_{4}$ tetrahedra. The $\mathrm{GdF}_{6}$ and $\mathrm{K}(1) \mathrm{F}_{6}$ octahedra are linked together by the $\mathrm{F}(3)$ fluorine atoms and form chains which expand along the $c$ direction. The site symmetry of $\mathrm{Gd}^{3+}$ ions is $C_{i}$ and the nearest $\mathrm{Gd}^{3+}$ ions are separated by more than $0.6 \mathrm{~nm}$. Structural data of the compounds under study are gathered in Table 1 .

\subsection{Luminescent properties of $E u^{3+}$ and $G d^{3+}-E u^{3+}$ energy transfer}

Spectroscopic parameters characterising luminescence of $\mathrm{Eu}^{3+}$ ions in the three matrices are gathered in Table 2. The $\mathrm{Eu}^{3+}$ ion with its unsplit ${ }^{7} \mathrm{~F}_{0}$ ground state is a convenient probe of strength and symmetry of the crystal field at cationic sites. It can be seen in the Table 2 that the crystal-field splitting of multiplets and relative energies of the crystal-field components do not depend significantly on the host. Relaxation dynamics of the $\mathrm{Eu}^{3+}$ excited states is influenced strongly, however. The contribution of multiphonon relaxation to the ${ }^{5} \mathrm{D}_{0}$ decay is negligible owing to a large energy separation between emitting level and the next lower one. As a consequence, the ${ }^{5} \mathrm{D}_{0}$ measured lifetimes may be considered as radiative lifetimes. Their values differ considerably (see Table 2) in the three systems studied. This indicates that degree of mixing of opposite parity functions into the $4 \mathrm{f}$ functions so as to relax the parity selection rules is significantly different. The ${ }^{5} \mathrm{D}_{2}$ decay is governed by multiphonon relaxation. Relation between multiphonon relaxation rates and cut-off phonon energy in the three systems studied is not consistent with dependence predicted by energy gap law which states that the lowest order process is the most likely to occur. This implies different electron-phonon coupling or contribution of lower energy phonons in multiphonon relaxation process.

In the three systems studied the luminescence originating in the ${ }^{5} \mathrm{D}_{0,1,2}$ multiplets of $\mathrm{Eu}^{3+}$ appear when excitation wavelength is scanned in the VUV-UV spectral range between $\sim$ 100 and $330 \mathrm{~nm}$, exactly.

Excitation spectra of $\mathrm{Eu}^{3+}$ emission obtained under such excitation have a broad band appears between about $175 \mathrm{~nm}$ and the host absorption edge located at about $125 \mathrm{~nm}$. It is believed to be associated with the $\mathrm{Eu}^{3+}-\mathrm{F}^{-}$charge transfer transition. At longer wavelengths a rich excitation spectra contain lines associated with $\mathrm{Gd}^{3+}$ and $\mathrm{Eu}^{3+}$ transitions. Excitation spectra of the ${ }^{5} \mathrm{D}_{0}$ and ${ }^{5} \mathrm{D}_{1}$ emissions, acquired from the 1.5 at $\% \mathrm{Eu}^{3+}: \mathrm{K}_{5} \mathrm{Li}_{2} \mathrm{GdF}_{10}$ single crystal at room temperature, are compared in Fig. 2. The excitation spectrum of the ${ }^{5} \mathrm{D}_{1}$ emission is inverted in this figure for the sake of clarity. It can be seen that the intensities of $\mathrm{Eu}^{3+}$ lines are the same for the both spectra, whereas the intensities of $\mathrm{Gd}^{3+}$ lines are significantly higher in the ${ }^{5} \mathrm{D}_{0}$ excitation spectrum. Accordingly, the energy transfer mechanism, which feeds the ${ }^{5} \mathrm{D}_{0}$ level, bypasses the ${ }^{5} \mathrm{D}_{1}$ level of $\mathrm{Eu}^{3+}$. At excitation wavelengths equal to $202 \mathrm{~nm}$ or shorter, the photon-cutting mechanism involving cross-relaxation scheme, depicted in Fig. 1, takes place. At longer excitation wavelengths a more complex mechanism contributes. A three-ion mechanism in which $\mathrm{Gd}^{3+}$ excitation is transferred simultaneously to two nearby $\mathrm{Eu}^{3+}$ ions can account for the experimental results but this hypothesis has to be verified. 


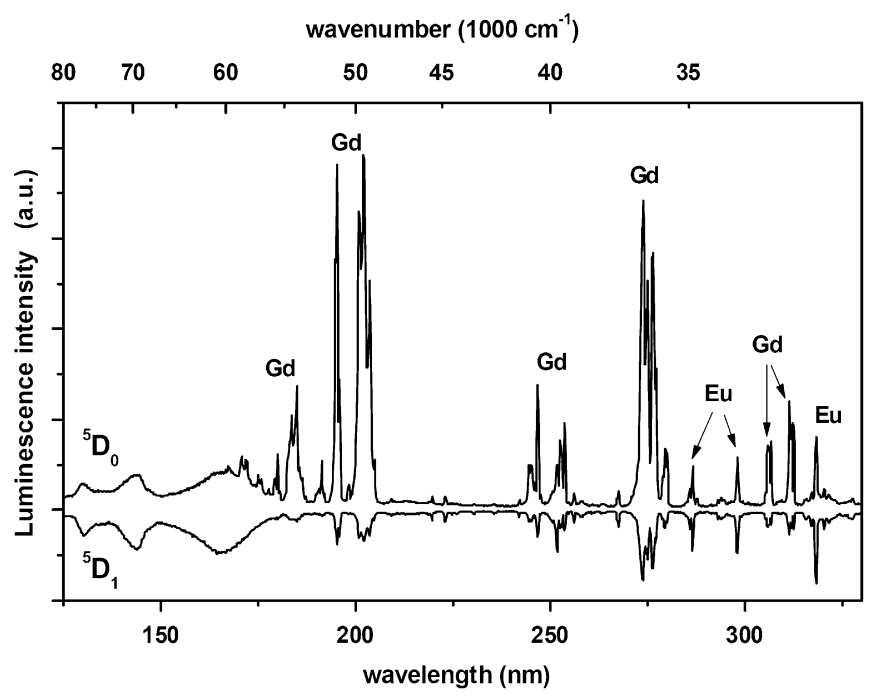

Fig. 2. Excitation spectra of the ${ }^{5} \mathrm{D}_{0}$ and ${ }^{5} \mathrm{D}_{1}$ emission (inverted) recorded at room temperature for the single crystal of $\mathrm{K}_{5} \mathrm{Li}_{2} \mathrm{GdF}_{10}$ containing 1.5 at $\%$ of $\mathrm{Eu}^{3+}$.

\subsection{Luminescent properties of $\mathrm{Pr}^{3+}$ and $\mathrm{Pr}^{3+}-\mathrm{Gd}^{3+}$ energy transfer}

The visible emission in the crystals doped with trivalent praseodymium is associated with transitions originating in the ${ }^{3} \mathrm{P}_{0}$ and ${ }^{1} \mathrm{D}_{2}$ multiplets and terminating in the ${ }^{3} \mathrm{H}_{J}$ and ${ }^{3} \mathrm{~F}_{J}$ multiplets, all belonging to the $4 \mathrm{f}^{2}$ configuration. Lifetime of luminescence originating in the ${ }^{3} \mathrm{P}_{0}$ level amounts to $41 \mu \mathrm{s}$ in 1 at $\% \operatorname{Pr}: \mathrm{K}_{3} \mathrm{GdF}_{6}$ and to $51 \mu \mathrm{s}$ in 1 at $\% \operatorname{Pr}: \mathrm{K}_{5} \mathrm{Li}_{2} \mathrm{GdF}_{10}$, at room temperature. Relatively longer lifetimes, of the order of hundreds of microseconds, were found for the ${ }^{1} \mathrm{D}_{2}$ level.
However, the ${ }^{1} \mathrm{D}_{2}$ emission has to be excited directly because phonon energies of the host crystals are too low to provide the excitation by multiphonon relaxation from higher energy levels. Accordingly, all $\operatorname{Pr}^{3+}$ emission lines in the visible range, recorded upon excitation in the blue, are associated with transitions originating in ${ }^{3} \mathrm{P}_{0}$. The emission spectra recorded upon excitation in the VUV spectral region (between 150 and $220 \mathrm{~nm}$ ) do not contain additional lines characteristic for the ${ }^{1} \mathrm{~S}_{0}$ emission. Such results indicate that in systems studied the ${ }^{1} \mathrm{~S}_{0}$ level is located higher than the lowest energy $5 \mathrm{~d}$ levels of $\operatorname{Pr}^{3+}$. Fig. 3 shows the emission spectrum of 1 at $\%$ Pr: $\mathrm{K}_{3} \mathrm{GdF}_{6}$ excited at $195 \mathrm{~nm}$. The spectrum consists of a huge band, centred at $32000 \mathrm{~cm}^{-1}$, related undoubtedly to the ${ }^{6} \mathrm{P}_{J}{ }^{-}{ }^{8} \mathrm{~S}_{7 / 2}$ transition of $\mathrm{Gd}^{3+}$, and of much weaker group of closely spaced lines between 15500 and $17000 \mathrm{~cm}^{-1}$. This part of spectrum is significantly more complex than that recorded upon excitation into the ${ }^{3} \mathrm{P}_{J}$ multiplets of $\operatorname{Pr}^{3}$ since it contains lines related to the ${ }^{6} \mathrm{G}_{7 / 2}{ }^{-6} \mathrm{P}_{7 / 2,5 / 2}$ transitions of $\mathrm{Gd}^{3+}$. The appearance of lines associated with emission of gadolinium in the spectrum excited in the UV range implies that the $\mathrm{Pr}^{3+}-\mathrm{Gd}^{3+}$ energy transfer takes place. This conclusion is confirmed by the UV excitation spectra of the $\operatorname{Pr}^{3+}$ emission at $607.8 \mathrm{~nm}$ and of the $\mathrm{Gd}^{3+}$ emission at $312 \mathrm{~nm}$, shown in Fig. 4. The excitation spectrum of the $\mathrm{Pr}^{3+}$ emission consists of a broad double band stretching from about $225-160 \mathrm{~nm}$, which we assign to the $\mathrm{f}-\mathrm{d}$ transitions of the $\mathrm{Pr}^{3+}$ ions. Its spectral position is consistent with the corresponding $\mathrm{f}-\mathrm{d}$ bands in the excitation spectra reported for other fluoride crystals doped with trivalent praseodymium (Kück et al., 2005).

It can be seen in Fig. 4 that the double band assigned above to the $\mathrm{f}-\mathrm{d}$ transitions of $\mathrm{Pr}^{3+}$ contributes to the excitation spectrum of the ${ }^{6} \mathrm{P}_{J}-{ }^{8} \mathrm{~S}_{7 / 2}$ transition of $\mathrm{Gd}^{3+}$ at $312 \mathrm{~nm}$. This is evidence

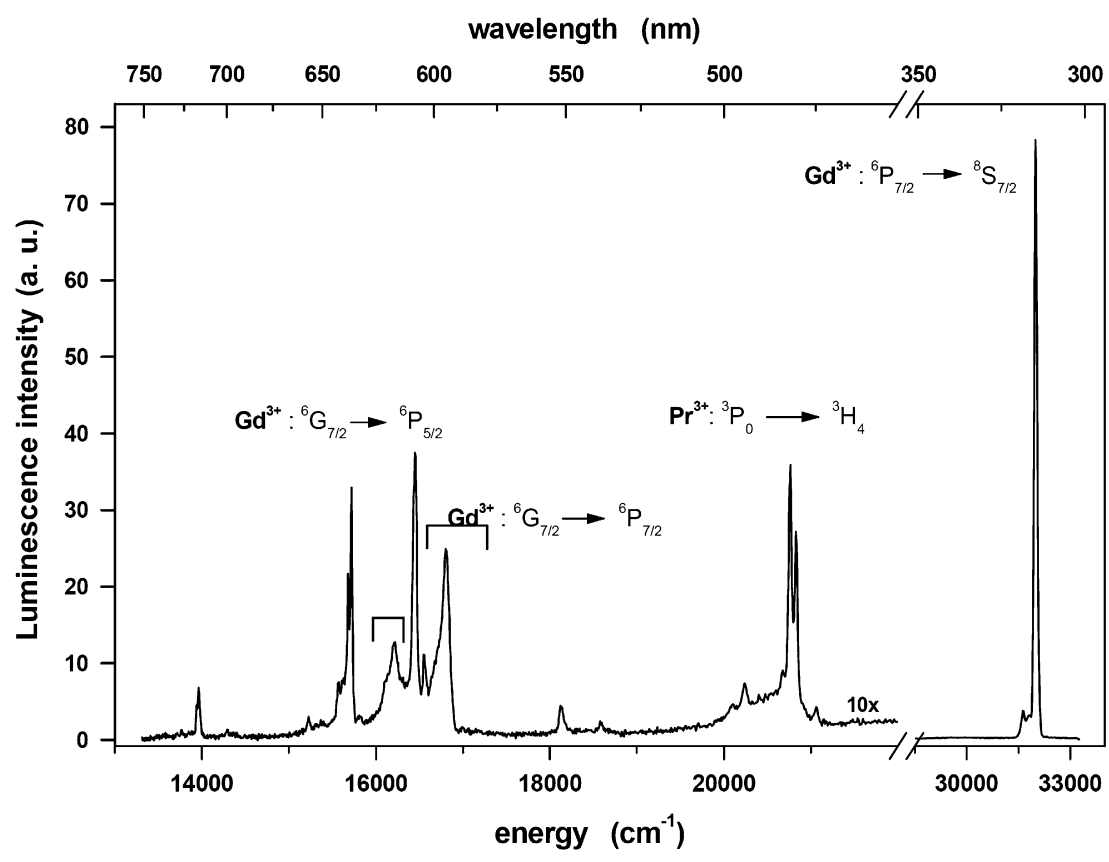

Fig. 3. Emission spectrum of 1 at $\% \operatorname{Pr}: \mathrm{K}_{3} \mathrm{GdF}_{6}$ recorded at $9 \mathrm{~K}$ upon excitation at $195 \mathrm{~nm}$. 


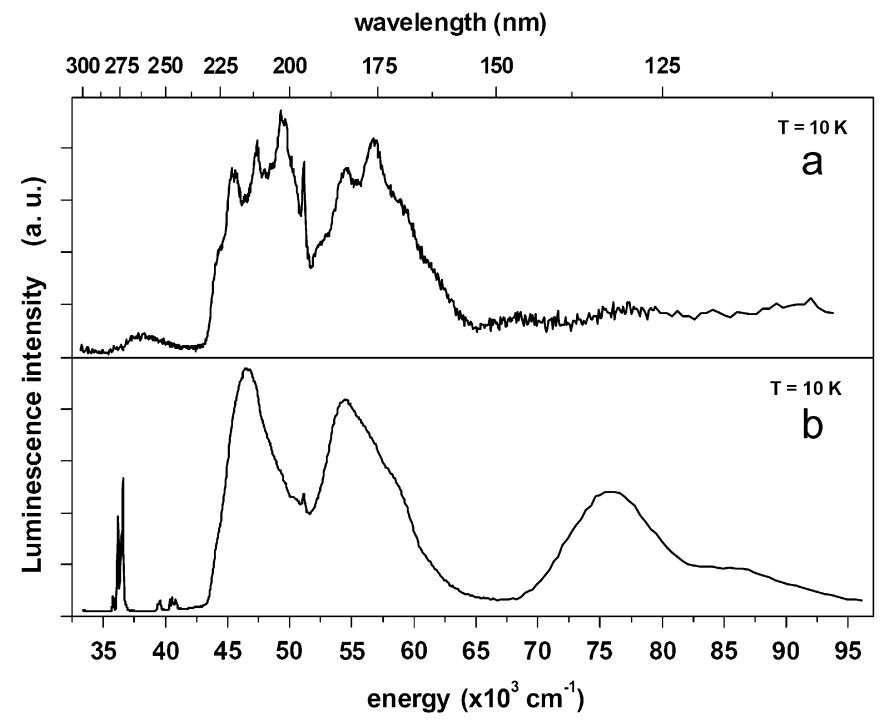

Fig. 4. Excitation spectra of the $\operatorname{Pr}^{3+}$ emission at $607.8 \mathrm{~nm}$ (a) and of the $\mathrm{Gd}^{3+}$ emission at $312 \mathrm{~nm}$ (b), recorded for the 1 at $\%$ Pr: $\mathrm{K}_{3} \mathrm{GdF}_{6}$ crystal at $9 \mathrm{~K}$.

that the energy transfer from the $5 \mathrm{~d}$ levels of praseodymium to the high energy levels belonging to the $4 \mathrm{f}^{7}$ configuration of gadolinium takes place. The intensity of this band in the excitation spectrum is even higher than intensities of the $\mathrm{Gd}^{3+}$ lines associated with the ${ }^{8} \mathrm{~S}_{7 / 2}{ }^{6} \mathrm{I}_{J}$ and the ${ }^{8} \mathrm{~S}_{7 / 2}{ }^{6} \mathrm{D}_{J}$ transitions around 270 and $250 \mathrm{~nm}$, respectively. The excitation energy is transferred from praseodymium ions to the ${ }^{6} \mathrm{G}_{J}$ and/or higher energy levels of $\mathrm{Gd}^{3+}$, as indicated by the contribution of $\mathrm{Gd}^{3+}$ lines to the emission spectrum shown in Fig. 3.

\section{Summary and conclusions}

Crystal structures and spectroscopic features of $\mathrm{Eu}^{3+}$ and $\mathrm{Pr}^{3+}$ in fluorides of gadolinium and alkali metals differing in shape and size of $\mathrm{Gd}^{3+}$ surrounding and energy of lattice vibrations were determined.

In the systems studied, the $\mathrm{Eu}^{3+}$ ion shows an intense visible luminescence upon the VUV and UV excitation into the $\mathrm{Gd}^{3+}$ levels. The cross-relaxation process contributing to the photoncutting phenomenon was evidenced in the $\mathrm{K}_{5} \mathrm{Li}_{2} \mathrm{GdF}_{10}$ : $\mathrm{Eu}^{3+}$ system.

An efficient energy transfer from the $5 \mathrm{~d}$ levels of $\mathrm{Pr}^{3+}$ to high energy levels of $\mathrm{Gd}^{3+}$ occurs in the systems studied. No clear trend in the relationship between the characteristics of fluorine ion coordination polyhedron around rare earth ions and their spectroscopic properties was found, however.

\section{Acknowledgements}

This work was supported by the European CommunityResearch Infrastructure Action under the FP6 "Structuring the European Research Area" Programme through the Integrated
Infrastructure Initiative "Integrating Activity on Synchrotron and Free Electron Laser Science".

We are grateful to Toyo Tanso Co., Ltd., Osaka, Japan for providing high quality IG-110 purified graphite.

The Polish Committee for Scientific Research partly supported this work as research project in 2005-2007.

\section{References}

Babin, V., Oskam, K.D., Vergeer, P., Meijerink, A., 2004. The role of $\mathrm{Pb}^{2+}$ as a sensitizer for $\mathrm{Gd}^{3+}-\mathrm{Eu}^{3+}$ downconversion couple in fluorides. Rad. Meas. 38, 767-770.

Dorenbos, P., 2000. 5d-Level energies of $\mathrm{Ce}^{3+}$ and crystalline environment. I. Fluoride compounds. Phys. Rev. B 62, 15640-15649.

Guyot, Y., Collombet, A., Somatri, T., Tkachuk, A., Joubert, M.-F., 2002. Spectral and dynamic study of the broad band UV $4 \mathrm{f}^{2}-4 \mathrm{f}^{3}$ emission in Nd-doped double sodium yttrium fluoride crystals and comparison with Nd: LiYF 4 . J. Alloys Compd. 341, 174-178.

Karimov, D.N., Kirm, M., Makhov, V.N., Ouvarova, T.V., Vielhauer, S., Zimmerer, G., 2001. VUV spectroscopy of a new fluoride system $\mathrm{NaF}-(\mathrm{Er}, \mathrm{Y}) \mathrm{F}_{3}$. Opt. Mater. 16, 437-444.

Krupa, J.C., Queffelec, M., 1997. UV and UVU optical excitations in wide band gap materials doped with rare earth ions: $4 \mathrm{f}-5 \mathrm{~d}$ transitions. J. Alloys Compd. 250, 287-292.

Kück, S., Sokólska, I., Henke, M., Scheffler, T., Osiac, E., 2005. Emission and excitation characteristics and internal quantum efficiencies of vacuumultraviolet excited $\mathrm{Pr}^{3+}$-doped fluoride compounds. Phys. Rev. B 71, 165112-1-165112-15.

Loh, E., 1966. Lowest $4 \mathrm{f}-5 \mathrm{~d}$ transition of trivalent rare-earth ions in $\mathrm{CaF}_{2}$ crystals. Phys. Rev. 147, 332-335.

Makhov, V.N., Khaidukov, N.M., Kirikova, N.Yu., Kirm, M., Krupa, J.C., Ouvarova, T.V., Zimmerer, G., 2000. VUV emission of rare-earth ions doped into fluoride crystals. J. Lumin. 87-89, 1005-1007.

Rodnyi, P.A., Mikhailik, V.B., Stryganyuk, G.B., Voloshinovskii, A.S., van Eijk, C.W.E., Zimmerer, G.F., 2000. Luminescence properties of Ce-doped $\mathrm{Cs}_{2} \mathrm{LiLaCl}_{6}$ crystals. J. Lumin. 86, 161-166.

Ryba-Romanowski, W., Gołąb, S., Dominiak-Dzik, G., Solarz, P., 2002. Eu ${ }^{3+}$ luminescence and $\mathrm{Gd}^{3+}-\mathrm{Eu}^{3+}$ energy transfer in $\mathrm{K}_{5} \mathrm{Li}_{2} \mathrm{GdF}_{10}: \mathrm{Eu}^{3+}$. Appl. Phys. A 74, 581-586.

Solarz, P., Pietraszko, A., Dominiak-Dzik, G., Ryba-Romanowski, W., 2004. Crystal structure and spectroscopic properties of a new fluoride compound $\mathrm{Na}_{2} \mathrm{~K}_{2} \mathrm{NdF}_{7}$. Chem. Phys. Lett. 400, 286-289.

Sommerdijk, L., Bril, A., Jager, A.W., 1974. Two photon luminescence with ultraviolet excitation of trivalent praseodymium. J. Lumin. 8, 341-343.

Szczurek, T., Schlesinger, M., 1985. In: Jeżowska-Trzebiatowska, B., Legendziewicz, J., Stręk, W. (Eds.), Rare Earth Spectroscopy. World Scientific, Singapore, pp. 309-330.

Wegh, R.T., Meijerink, A., 1996. First observation of visible luminescence from trivalent gadolinium. Acta Phys. Polon. A90, 333-337.

Wegh, R.T., Meijerink, A., 1999. Spin-allowed and spin-forbidden $4 \mathrm{f}^{n}-4 \mathrm{f}^{n-1} 5 \mathrm{~d}$ transitions for heavy lanthanides in fluoride hosts. Phys. Rev. B 60, 10820-10830.

Wegh, R.T., Donker, H., Meijerink, A., Lamminmaki, R.J., Holsa, J., 1997. Vacuum ultraviolet spectroscopy and quantum cutting for $\mathrm{Gd}^{3+}$ in $\mathrm{LiYF}_{4}$. Phys. Rev. B 56, 13841-13848.

Wegh, R.T., Donker, H., Oskam, K.D., Meijerink, A., 1999. Visible quantum $\mathrm{Eu}^{3+}$ cutting in doped gadolinium fluorides via downconversion. J. Lumin. 82, 93-104.

Wojtowicz, A.J., Drozdowski, W., Wiśniewski, D., Lefaucheur, J.-L., Gałązka, Z., Zhenhui, G., Łukasiewicz, T., Kisielewski, J., 2006. Scintillation properties of selected monocrystals activated with $\mathrm{Ce}$ and Pr. Opt. Mater. 28, 85-93. 